\title{
A identidade latino-americana na visão dos intelectuais da década de 1960
}

HELOISA JOCHIMS REICHEL*

\begin{abstract}
Resumo: O artigo aborda as representações sobre a identidade latino-americana, construídas pelos intelectuais durante a década de 1960, período de exacerbação da guerrafria na região e, ainda, de forte influência do pensamento cepalino. Buscando caracterizar redes de intelectuais que se formaram, a análise privilegiou três periódicos que gozaram de grande conceito no período: Revista Mexicana de Sociologia, Cuadernos Americanos e Desarrollo Económico.
\end{abstract}

\begin{abstract}
This article deals with the representations on the Latin American identity, developed by intellectuals during the 1960 decade, which was a period of exacerbation of the Cold War in that particular region and also of strong influence of Cepalino thought. In an attempt to characterize nets of intellectuals thus formed the present analysis focuses on three periodicals that shared great success at that time, namely Revista Mexicana de Sociologia, Cuadernos Americanos e Desarrollo Económico.
\end{abstract}

Palavras-chave: América Latina. Identidade. Intelectuais.

Key words: Latin America. Identity. Intellectuals.

A preocupação com a identidade continental nas Américas se fez presente entre os pensadores e políticos desde o momento em que se iniciou o processo de independência nas colônias ibéricas. Desde então, a proposta de unidade da América hispânica, de Simon Bolívar, tornou-se referência simbólica à concepção de uma América unida em torno de elementos identitários comuns. Ao final do século XIX, surgiram duas concepções claramente antagônicas: de um lado, a de José Marti, que, com a expressão Nuestra América, afirmava haver diferença entre a América dos países que ficam ao sul do Rio Grande e a América dos norte-americanos, e, de outro, a protagonizada pelos Estados Unidos, que, conhecida por pan-americanismo, visava à integração de todos os países da América.

Doutora em História Social. Docente do Programa de Pós-Graduação em História da UNISINOS. E-mail: hreichel@unisinos.br

Estudos Ibero-Americanos. PUCRS, v. XXXIII, n. 2, p. 116-133, dezembro 2007 
As duas tendências conviveram durante a primeira metade do século passado, encontrando adeptos entre os intelectuais, que se dividiam entre uma e outra, de forma mais ou menos equilibrada. ${ }^{1}$ Entretanto, a divisão ideológica surgida com a guerra-fria e as dificuldades enfrentadas pelas economias dos países latinoamericanos após a Segunda Guerra Mundial propiciaram que, entre os intelectuais, passasse a haver um predomínio daquela que defendia a unidade latino-americana. Hugo Cancino (2004, p. 15) escreveu sobre a posição ideológica desses intelectuais:

En la década crítica de los años 60 y 70, fue el período que el historiador chileno Mario Góngora denominó de los proyectos de 'planificación total', los intelectuales latinoamericanos se encontrarón mayoritariamente ubicados en el bloque social e político de los proyectos socialistas. Allí, como militantes comprometidos con esta causa jugaron el rol de propagandistas e ideólogos y también de dirigentes políticos. El marxismo, en sus diversas versiones, stalinistas, estructuralistas, etc. conquistó los claustros universitarios e influyó decisivamente desde las instancias de poder universitario en la orientación de estudios, principalmente en Ciencias Sociales y Letras. [...]. Frente al marxismo académico, a los proyectos modernizadores socialistas, y a los proyectos dasarrollistas, se localizaron minúsculos bolsones de resistencia 'tradicionalista' en el plano de las ideas representada por los grupos integristas católicos, como 'Fiducia', Sociedad por la defensa de la Sociedad, Família y Propriedad, fundada por el profesor brasileño Plinio Correa de Oliveira.

Neste artigo, analisamos a reflexão de intelectuais de esquerda acerca da América Latina, publicada em revistas especializadas. A opção por essa fonte de pesquisa esteve condicionada, em parte, pela abundância e pela diversidade da produção intelectual da época, bem como pela impossibilidade de reunir a totalidade das publicações dos autores. Porém, é importante afirmar a validade e pertinência da mesma para com nossos objetivos. Sirinelli (in: Rémond, 1996, p. 248-249) reconheceu que as revistas constituem um meio importante para alcançar um conhecimento acerca da produção intelectual, tendo em vista que, através da seleção feita pelo conselho editorial e dos laços de confiança, ou até mêsmo de repúdio, que se estabelecem entre autores e leitores, elas vão formando "redes" que possibilitam identificar a estrutura do campo intelectual.

1 Muitos autores destacam que, já nos anos 1920, o anti-americanismo se sobressaía nas análises dos intelectuais, junto com o nacionalismo. 
Selecionamos três periódicos que gozaram de bom conceito no meio acadêmico e intelectual, e tiveram circulação expressiva em diversos países latino-americanos durante o período em foco. São eles: Revista Mexicana de Sociologia, Cuadernos Americanos, ambos editados no México, e Desarrollo Económico, publicada na Argentina. O critério para a seleção dos mesmos foi o de estarem identificados com a dimensão da nação latino-americana e o objetivo da análise foi de verificar quais as representações acerca da identidade da América Latina que os intelectuais privilegiaram.

Para analisar a identidade latino-americana na visão dos intelectuais de meados do século XX, ${ }^{2}$ baseamo-nos no conceito representações. Bronislaw Baczko (1985) continua sendo a principal referência para a compreensão do mesmo, seja porque deu contribuições fundamentais para o seu entendimento, seja porque pertence ao grupo de intelectuais que considera o imaginário como parte integrante do real, vinculando-o com a dinâmica e com o contexto social.

O conceito identidade também foi considerado em nossa fundamentação teórica. Ele tem sido objeto de estudo de antropólogos, historiadores, sociólogos, psicólogos, etc., e apresenta, como principais aspectos constitutivos, os sentimentos de pertencimento (nós) e de alteridade (outro). É importante verificar, ainda, a confluência do conceito identidade com o de representação, identificada principalmente em Bourdieu (1989), que, ao focalizar o tema região, nos mostrou o quanto o último atua decisivamente na definição do primeiro.

\section{A Identidade Latino Americana na Revista Mexicana de Sociologia}

A Revista Mexicana de Sociologia é uma publicação do Instituto de Investigações Sociais da Universidade Autônoma do México (UNAM) e se mantém ativa até os dias atuais. Foi fundada em 1939, sendo o periódico mais antigo, no campo das ciências sociais, da América Latina. A periodicidade da revista é trimestral e os artigos são publicados em espanhol e inglês.

A revista, segundo seus editores, pretende ser um espaço que abriga a pluralidade de concepções acerca da realidade social e,

2 Período que está fortemente relacionado com a Revolução Cubana que ocorreu em janeiro de 1959. Antes dessa data, já havia a mobilização das tropas guerrilheiras de Fidel Castro em Sierra Maestra. Até 1961, porém, Cuba não havia ingressado formalmente no bloco soviético. 
como tal, "incluye temas sociológicos contemporáneos y de disciplinas afines, estos pueden ser teóricos y/o empíricos sin limitaciones de fronteras geográficas o culturales". ${ }^{3}$ Essas características são reconhecidas no site eletrônico da revista através do texto abaixo, que resume a produção publicada no periódico desde o momento de sua criação até o presente:

Ha difundido, entre su amplia gama de lectores, las más variadas corrientes del pensamiento social y la problemática sociopolítica, las polémicas y debates de reconocidos académicos que han dejado huella en las Ciencias Sociales. También se destaca por su interés en divulgar resultados de investigación y propuestas metodológicas que permiten apoyar con creatividad, originalidad y confiabilidad los análisis y los debates.

A análise que realizamos acerca da rede de intelectuais que publicou na Revista Mexicana de Sociologia concentrou-se nos volumes editados entre 1957 e 1961, período a que tivemos acesso aos exemplares. Os autores, em grande número, eram acadêmicos da UNAM, ou pertenciam a instituições universitárias de outros países da América. Entre eles, encontram-se Carlos M. Rama, professor da Universidade Nacional do Uruguai, Aldo E. Solari, da Faculdade de Direito e Ciências Sociais e do Instituto de Profesores "Artigas", também do Uruguai, Roberto Mac-Lean y Estenós, Presidente do Instituto Peruano de Sociologia e representante do Peru na Organização das Nações Unidas para Educação, Ciências e Cultura, José Rafael Mendoza, Diretor do Instituto de Investgações Sociais da Universidade de Santa Maria de Caracas, na Venezuela, Miguel Leon Portilla, subdiretor do Instituto Indígena Interamericano, com sede no México, Roberto Agramonte da Universidade de La Habana de Cuba, entre outros. Participavam, porém em menor número, autores da Europa e dos EUA que focalizavam, em seus artigos, a problemática latino-americana. Dentre eles, citamos Êmile Sicard do Centro de Estudos e Investigações Humanas, do Instituto Internacional de Estudos e Investigações Diplomáticas e da Escola de Altos Estudos Sociais de Paris, além de membros de instituições universitárias norte-americanas, como John B. Knox da Universidade do Tennessee, e Willian Foote Whyte da Universidade de Cornell/Nova York.

$\mathrm{O}$ primeiro elemento que se destaca no que diz respeito à identidade latino-americana é que os autores, em sua grande maioria, adotavam a perspectiva de uma América Latina una, delineando-a

3 Retirado do site da revista que se encontra na página eletrônica da UNAM http://www.ejournal.unam.mx/rms/about_rms.html 
enquanto um continente imaginário. Nessa representação, a unidade não correspondia ao traçado geográfico do continente denominado América, mas, sim, a uma parte deste, formado pelos países da América do Sul, da América Central e pelo México. Valdez (1959), por exemplo, representou essa unidade, relacionando aspectos que se faziam presentes em todos os países latinoamericanos e que poderiam levar a uma revolução, como a luta pela conquista das independências, os governos tirânicos que se instalaram e a não obtenção da estabilidade política e econômica após essa conquista, além de presença de uma população inculta e pobre em todo o continente. Assinalou, também, a existência de um sentimento nacional proveniente do espírito indígena, do regionalismo espanhol, dos regimes tirânicos, do narcisismo, da preocupação territorial e de um complexo de inferioridade.

Mesmo quando os artigos priorizavam questões referentes a um determinado país, o fizeram de modo a apontar semelhanças e/ou afastamentos com os demais da América Latina. Como exemplo, podemos citar um artigo que abordou o processo de independência do Haiti (Saint-Louis, 1959). Nele, o autor assinalou a comunhão desse país com o restante da região, pois considerava que a luta pela Independência do Haiti ocorrera dentro do "mismo fenómeno de los paises latinoamericanos, con la diferencia de que la clase dirigente haitiana no es blanca" (Saint-Louis, 1959, p. 205).

A identidade latino-americana foi focalizada, também, através de análises que davam destaque às diferenças existentes entre a região e outros continentes. Andrews (1957, p. 430) referiu que "las clases sociales de Hispanoamérica también tienen caracteres diferentes de las de otros países y continentes". Antes, ao iniciar seu artigo, colocara que existem diversos fatores que diferenciam os latino-americanos da "Europa, Ásia y América sajona" (Andrews, 1957, p. 423). Outro autor considerou que a América Latina encontrava-se num grau de desenvolvimento superior ao do "Cercano o del Lejano Oriente, del Magreb o del África Negra" (Alba, 1960, p. 783), e considerou a classe média latino-americana, composta por industriais, comerciantes, técnicos, burocratas e dirigentes de empresas, como capaz de tomar iniciativas próprias, diferentemente da européia que acompanhava as outras classes.

Além da perspectiva espacial latino-americana e da ênfase às questões relativas ao pertencimento e à alteridade, podemos perceber a afirmação da nação latino-americana através de alguns temas que foram focalizados predominantemente. São eles:

O desenvolvimento e a reforma agrária - Estes dois temas apareceram intimamente relacionados, pois, seguindo a interpretação da 
CEPAL, para alcançar o desenvolvimento, a reforma agrária se fazia necessária. Porém, já era possível identificar, em alguns autores, a radicalização político-ideológica que se fez presente entre os intelectuais ao final da década de 1950.

Considerando a teoria da CEPAL apenas reformista e pouco eficaz porque se estruturava a partir da racionalidade capitalista, Álvaro Diez assinalou que a integração latino-americana só podia se realizar com sucesso "dentro de los moldes socialistas" (Diez, 1960, p. 778), e que os intelectuais latino-americanos tinham papel de destaque a desempenhar nesse processo, pois deviam agir em prol da "revolución económica destinada a emancipar a los países de América Latina del dominio del imperialismo y de la oligarquía" (Diez, 1960, p. 779). Segundo ele, a questão da terra era central para que, na América Latina, se iniciasse um período de profunda mudança, pois o elemento que impedia o desenvolvimento da economia era "la concentración de terra en manos de los latifúndios semifeudales" (Diez, 1960, p. 756).

Partindo da premissa de que elementos desorganizadores da economia provocavam o atraso no desenvolvimento da região, Mac-Lean y Estenós foi outro autor que analisou a relação desenvolvimento e reforma agrária. Assinalou o atraso na organização agrária, apontando como causa o latifúndio que "produce languidez y pobreza" (Estenós, 1958, p. 388). Segundo ele, não era possivel impulsionar o aumento da produtividade da terra sem pôr fim aos elementos feudalizantes, sendo, para isso, necessário acabar "previamente com el latifundio" (Estenós, 1958, p. 399). Para Y olanda Ortiz, a questão agrária também era um elemento que caracterizava o atraso dos países latino-americanos e assinalou que, para o desenvolvimento do meio urbano, se fazia necessária a "reforma las estructuras agrárias [...] que debería acompañarse de la modernización y mecanización de la agricultura" (Ortiz, 1957, p. 37). William F. Whyte, por sua vez, colocou a questão da terra como um obstáculo à industrialização, causada pela falta de resolução dos problemas rurais, pois existia "una estrecha relación entre los problemas rurales y los problemas industriales" (White, 1961, p. 786).

A dependência - Alguns focalizaram a dependência econômica e outros a cultural. Relacionaram-na com o desenvolvimento, considerando-a indispensável para a conquista da "verdadeira independência". De acordo com o pensamento da época, em que os movimentos de emancipação produziam apenas a ruptura dos laços políticos coloniais, afirmou que o processo de independência dos países latino-americanos apenas significou a mudança da de- 
pendência de "una metrópoli regida por lo político a una dependencia regida en lo econômico, en lo social, en lo político, en lo cultural" (Villegas, 1960, p. 565), de modo a ser, este novo tipo de dependência, um entrave para o desenvolvimento dos países. Mac-Lean y Estenós, por sua vez, considerou que, no século vinte, na América Latina, "surge un nuevo tipo de colonialismo econômico" sob a forma de "tributarios del capitalismo norteamericano" (Estenós, 1958, p. 387).

A dependência cultural também foi objeto da atenção dos intelectuais que publicaram na Revista Mexicana de Sociologia. Nesse sentido, Ortiz afirmou que um dos elementos que caracterizam os países latino-americanos é o "retardo cultural inconmensurable" (Ortiz, 1957, p. 35). Alba (1960), por sua vez, justificou esse atraso através da grande aceitação, na América Latina, de idéias estrangeiras, como o enciclopedismo, o positivismo, o marxismo e o keynesianismo. Dando continuidade a essa interpretação, Villegas chamou a atenção para a necessidade da construção de um pensamento próprio da América Latina, e combateu o que chamou de "situación colonial académica" (Villegas, 1958, p. 486). Chegou a afirmar que descolonizar a América Latina no terreno acadêmico significava contribuir para que o mesmo acontecesse no terreno econômico.

Índios e mestiços - os grupos sociais mais focalizados pelos autores foram os índios e os mestiços. A preocupação central dizia respeito ao aspecto da incorporação social e econômica dos mesmos. Os autores que apontaram as injustiças que os primeiros sofreram historicamente, não somente durante a colonização, mas, também, após a independência, destacaram que os índios, no período da conquista, saíram das cidades em que viviam, refugiando-se no campo para "escapar a la garra de sus opresores" (Estenós, 1958, p. 393), e que, no período da independência, "las comunidades indígenas... sofrieron también la agresión de la naciente República" (Estenós, 1958, p. 394).

A temática indígena foi relacionada à reforma agrária e ao desenvolvimento industrial. Como questão fundamental a ser resolvida para uma política destinada às comunidades indígenas, Estenós referiu a necessidade de se acabar "previamente con el latifundio" (Estenós, 1958, p. 399). Ortiz, por sua vez, ao tratar da dificuldade de adaptação do indígena ao meio urbano, assinalou que a dificuldade se devia à "desorientación que proviene de la falta de contacto anterior con un medio industrial" (Ortiz, 1957, p. 31), e sinalizou como um dos elementos para uma melhor adapta- 
ção a necessidade dos índios serem "alfabetizados" (Ortiz, 1957, p. 36).

O mestiço foi considerado o elemento que melhor representava a sociedade latino-americana por boa parte dos autores. ${ }^{4}$ Andrews, ao mesmo tempo em que considerava o mestiço como um tipo social que se fazia presente em todo território latinoamericano, disse ser esse um elemento humano "sui generis [...] que será un factor de enorme influencia en el mundo del porvenir" (Andrews, 1957, p. 429). Sobre essa peculiar composição da sociedade latino-americana, justificou que os hispânicos que vieram para o continente americano não eram de etnia branca pura, pertencendo a diferentes grupos, assim como os índios, que também eram de distintas etnias. Ortiz focalizou o mestiço a partir da dificuldade que o mesmo apresentava para se adaptar ao meio urbano, assinalando que o mestiço era, no meio social, "un elemento intermédiario" (Ortiz, 1957, p. 33).

No mesmo artigo, o autor estendeu a problemática da adaptação ao meio urbano à população oriunda do meio rural, compôsta predominantemente por mestiços e indígenas. Para ele, nos países em desenvolvimento como os da América Latina, essa dificuldade existia devido ao profundo desequilíbrio entre cidade e campo, ao atraso técnico e cultural do setor rural, ao "mantenimiento de estructuras agrarias semifeudales" (Ortiz, 1957, p. 35), além do analfabetismo e da precária qualidade de vida dos indígenas. Propôs, ainda, a racionalização e a planificação da migração sendo que "sólo quienes sean capaces de un mínimo de adaptación a condiciones dadas de vida, pueden ser autorizados para franquear las puertas de la ciudad" (Ortiz, 1957, p. 36). Para que isso acontecesse, impunha-se, ao poder público, a alfabetização dos mestiços e índios, a reforma agrária no sentido da modernização e mecanização da agricultura, a formação de cooperativas e sindicatos, além do investimento para manter o homem do campo no meio rural, adaptando-o a uma vida moderna "como para preparar el paso a la ciudad" (Ortiz, 1957, p. 37).

A mestiçagem foi, também, analisada a partir da perspectiva cultural. Andrews (1957) assinalou que as práticas culturais ex-pressavam a influência das tradições européias - adotadas majoritariamente pela classe alta e média - e das indígenas - adotadas

4 É possível que esse posicionamento tenha ocorrido devido ao fato da revista ser publicada no México, país sob forte influência do pensamento de José Vasconcelos. Estenós, autor que valorizou os indígenas, era peruano, podendo estar sob influência do pensamento de Mariátegui sobre a identidade do homem latino-americano. 
majoritariamente pelas classes populares - entre os latinoamericanos. Essa mescla de tradições foi responsável pelas peculiaridades da América Latina no que tange à constituição das suas instituições sociais, como família, religião, educação e política, propriedade entre outras.

\section{A Identidade latino-americana na revista \\ Cuadernos Americanos}

A revista Cuadernos Americanos é uma publicação bimestral sob a responsabilidade do Centro Coordenador e Difusor de Estudos Latino Americanos da Universidade Autônoma do México (UNAM). Fundada em 1942, ela divide seu histórico em três épocas: a primeira abarca o vol. I (1942) até o vol. 261 (1984), correspondendo ao período em que seu fundador, o intelectual mexicano Jesús Silva Herzog foi seu diretor; a segunda corresponde a um breve período de transição, no qual foram editados os volumes de $\mathrm{n}^{\mathrm{o}} 262$ (1985) até o de $\mathrm{n}^{\mathrm{o}} 265$ (1986); e a terceira, chamada "NOVA ÉPOCA", inicia com o vol. 266 (1987), que perdura até os dias de hoje. Essa última etapa é indelevelmente marcada pela direção do filósofo mexicano Leopoldo Zea, a qual se estendeu de 1987 até 2004, ano em que o intelectual faleceu.

Para a realização desta análise, foram pesquisados os volumes editados nos anos de 1955, 1960, 1963, 1964, 1965 e 1966, tendo sido selecionados trinta e nove artigos. No período, a revista dividia seu sumário em quatro seções: Nuestro Tiempo, que tratava de assuntos contemporâneos ao período, de modo a constituir uma reflexão sobre problemas vivenciados pelos intelectuais. Aventura del Pensamiento, outra seção, trazia ensaios de cunho filosófico, além de analisar o pensamento de alguns intelectuais de destaque. Presencia del Pasado, na qual se encontravam artigos relativos a temas políticos como, por exemplo, o colonialismo e a independência, e sociais, como o dos índios, em determinados períodos históricos. Dimension Imaginária, outra seção, tratava de áreas do campo cultural convencional, como literatura, poesia, pintura, entre outros. Havia, também, mas não de forma periódica, a seção Hombres de Nuestra Linaje, seção que trazia homenagens a intelectuais, focalizando o pensamento dos mesmos.

Entre os autores que publicaram na revista Cuadernos Americanos, encontra-se seu fundador, Jesús Silva Herzog, professor emérito da UNAM, criador do Instituto Mexicano de Investigações Econômicas e da Revista Mexicana de Economia; foi autor, entre 
outras obras, de Breve história da Revolução Mexicana (1960) e Antologia do pensamento econômico-social, de Bodino a Proudhon (1963). Leopoldo Zea, criador do Centro de Estudos Latino Americanos da UNAM e autor, até aquele momento, de América como consciência (1953) e América na história (1957), foi outro assíduo colaborador da revista. Além desses, intelectuais e políticos de destaque no cenário latino-americano contribuíram com artigos. Dentre eles, destacam-se Alfredo Palácios, senador argentino, Carlos M. Rama, professor da Universidade da República do Uruguai, Salvador Allende, ainda candidato à presidência do Chile no período aqui focalizado, Camilo Dagum, intelectual argentino que foi professor nas universidades de Córdoba, Iowa, México, Paris, Ottawa, Milan e Bolonha.

Os artigos que foram publicados na revista demonstram que o periódico se achava vinculado ao pensamento predominante entre os intelectuais de esquerda e defendiam a existência da nação latino-americana. Os autores, como no periódico anterior, buscaram representar a identidade latino-americana através da comparação da região com outros países e/ou outros continentes. Podemos apontar duas imagens, que foram recorrentes. A primeira era resultado de um comparativo com os países industrializados da Europa e os EUA e, nela, a América Latina aparecia como unidade subdesenvolvida e objeto da interferência externa do imperialismo. A segunda delineava a unidade existente entre a América Latina, Ásia e África, baseando-a no fato de que elas "lograran con sus sacrificios la industrialización de las naciones occidentales" (Zea, 1964, p. 78), ao mesmo tempo em que tinham suas possibilidades de desenvolvimento inviabilizadas.

A revista Cuadernos Americanos representou a identidade da América Latina através dos temas que apresentamos a seguir.

O imperialismo - De forma muito próxima ao que os da revista anteriormente analisada denominaram de dependência, os autores identificaram os países industrializados como as principais expressões do imperialismo, sendo os EUA o agente principal. A dominação externa, quando ocorria na dimensão militar, na política, na econômica ou na cultural, foi considerada, também como já ocorrera no periódico anteriormente analisado, um importante entrave ao desenvolvimento da América Latina.

Entre os autores que relacionaram o imperialismo com a problemática do desenvolvimento, encontra-se Leopoldo Zea. Em seu artigo, "Latino América em la formación de nuestro tiempo", analisou a dependência da América Latina, considerando que a mesma vinha sendo "un simple campo de expansión" (Zea, 1965, p. 13) 
para os países da Europa e, mais recentemente, dos EUA. Ressaltou os efeitos negativos, para a América Latina, das políticas dos EUA, como o Destino Manifesto e a Doutrina Monroe, que entravavam o desenvolvimento da economia latino-americana. Do ponto de vista da ação militar, criticou a intervenção realizada pelos EUA nos países latino-americanos sob a justificativa de que era necessária para o combate ao comunismo. Porém, para ele, o que agravava ainda mais a situação, era o fato do imperialismo dos EUA encontrar apoio dentro da burguesia latino-americana e que "las seudoburguesías latinoamericanas no son outra cosa que amanuenses o guardianes celosos" (Zea, 1964, p. 75) dos interesses estrangeiros. Considerou que outro efeito negativo da intervenção dos países industrializados na América Latina consistia em que as forças estrangeiras forneciam "apoyo a viejas fuerzas feudales... orden que no impliba la aparición de naciones capases de competir con el progreso material, económico, alcanzado por las naciones occidentales" (Zea, 1964, p. 75). Seguindo a mesma linha de raciocínio de Zea, a intervenção econômica dos Estados Unidos foi objeto de alguns outros artigos como "El informe Prebisch y la realidad latino-americana", de Ramón Ramires Gómez (1963, p. 69) e "Hacia una teoria de los países atrasados", de Antonio Garcia (1955, p. 30).

Julio Larrea, no artigo "La educación y la vida internacional en la América Latina”, apontou, como já havíamos observado no periódico anterior, outro viés da intervenção estrangeira na América Latina. Ao considerar que pesquisadores dos países desenvolvidos, trabalhando "una determinada región señalada como atrasada, tratan de imponer... una impresión totalmente negativa... contra esa región" (Larrea, 1963, p. 7), destacou a necessidade de combater essa imagem com a construção de um caminho de independência intelectual na América Latina. Relacionou, assim, "la original contribuición de los intelectuales y educadores latinoamericanos" (Larrea, 1963, p. 13) à superação da dependência cultural e econômica.

Subdesenvolvimento e estruturas agrárias arcaicas - De acordo com as tendências interpretativas da época, os intelectuais que publicaram na revista Cuadernos Americanos representaram a identidade latino-americana através da compreensão de que a América Latina encontrava-se em um grau de desenvolvimento distinto ao alcançado pelos países da Europa e dos EUA, no chamado subdesenvolvimento. No artigo "Puerto Rico y la América Latina", afirmou-se que a América Latina encontrava-se num estágio de "subdesarrollo econômico" (Denis, 1963, p. 8) e que a "concentración de 
las tierras en grandes latifundios" (Denis, 1963, p. 8) impedia o desenvolvimento latino-americano. Em "El Equador en 1963", "el feudalismo" (Belfrage, 1964, p. 38) foi apontado como responsável pelo atraso em que se encontrava o país. Em "Perspectivas de la Conferencia Mundial dobre desarrollo y comercio", Gaitán apontou a necessidade da reforma agrária, identificando a concentração de terra existente na América Latina como a origem de "una escasa movilidad social y a un alto grado de analfabetismo, que traducen en obstáculo al desarrollo" (Gaitán, 1964, p. 44). Desse modo, assim como os que publicaram na Revista Mexicana de Sociologia, muitos deles assinalaram a necessidade de promover o desenvolvimento da América Latina através da reforma agrária.

Desenvolvimento econômico associado ao social - A industrialização foi identificada como o caminho a ser tomado para alcançar o desenvolvimento. O artigo "Una presentación de América Latina" referiu à necessidade de "industrializar más la América Latina y diversificar las producciones" (Arciniegas, 1965, p. 82). Segundo o autor, os países industrializados vendiam produtos por altos valores para os latino-americanos, ao mesmo tempo em que compravam desses por baixos preços, fator que impedia o desenvolvimento latino-americano, pois "parte de essa falta de desarrollo que nos enrostran está en que no nos dejan desarrollar" (Arciniegas, 1965, p. 81).

A elevação do padrão sócio-cultural das camadas populares, acompanhando o desenvolvimento econômico, mereceu grande atenção dos intelectuais que publicaram na revista Cuadernos Americanos. No artigo "El informe Prebisch y la realidad latinoamericana", Gómes assinalou a necessidade de iniciativas para o desenvolvimento latino-americano tendo "que acelerar su ritmo de desarrollo econômico y redistribuir el ingreso a favor de las masas populares" (Gómes, 1963, p. 10). Para o autor, "la estructura social prevaleciente en América Latina opone un serio obstáculo al progreso técnico y, por conseguinte, al desarrollo económico y social" (Gómes, 1963, p. 11), sendo estas manifestadas na falta de empresários de iniciativa, no privilégio na distribuição da riqueza e no alto consumo das camadas superiores.

História e futuro promissor - A história da América Latina serviu para representar a nação latino-americana, principalmente quando focalizava o passado comum de todos os países. Arciniegas, em "Una presentación de América Latina", considerou que, para tratar do momento em que vivia a América Latina, se fazia necessária uma abordagem de seu passado: "Si me he demorado em el 1500, es porque a 1965 hay que ponerle um telón de fondo" 
(Arciniegas, 1965, p. 76). Em "La educación y la vida internacional en la América Latina" (1965), a identidade latino-americana foi relacionada, por Julio Larrea, com o passado comum de colonização, o qual se constituía num entrave ao desenvolvimento.

Apesar de valoriazarem o passado, os intelectuais que publicaram em Cuadernos Americanos, seguindo uma expectativa que se fazia presente entre muitos especialistas, políticos e capitalistas na época, perpassavam a crença em um futuro promissor, apontando a existência de um "porvenir de Nuestra América" (Palácios, 1960, p. 51). Arciniegas, assinalando o crescimento industrial latinoamericano, referiu que algumas cidades latino-americanas "crecen más rapidamente que las ciudades europeas" (1965, p. 77). No artigo já citado "La educación y la vida internacional em la América Latina", o autor, mesmo tratando de um elemento específico, o movimento universitário ocorrido em Córdoba, Argentina, em 1918, procurou avaliar esse movimento como uma reafirmação da "fe en el destino latinoamericano" (1963, p. 10).

\section{A integração latino-americana na revista Desarrollo Econômico (DE)}

A revista Desarrollo Económico vem sendo publicada, na Argentina, desde 1961 até os dias de hoje. A instituição responsável por sua edição é o Instituto Económico y Social (I.D.E.S), associação civil sem fins lucrativos, de índole acadêmica, dedicada ao estudo de temas econômicos, políticos e culturais.

A revista tem sua linha editorial marcada pelo interesse em focalizar assuntos relativos à ordem econômica e social e a rede de intelectuais que ela congrega é, em sua grande maioria, formada por economistas, sociólogos e historiadores que se dedicam a refletir sobre os problemas de desenvolvimento que a América Latina.

Nos inícios da década de 1960, quando iniciou sua publicação, a perspectiva de uma identidade latino-americana se fazia muito presente nos artigos publicados, principalmente através da identificação de elementos que configuravam a noção de pertencimento. Nesse sentido, as palavras do chileno Cláudio Veliz, no artigo "La Mesa de Três Patas", demonstram que a unidade latinoamericana se superpunha aos nacionalismos:

É conveniente fazer um breve aparte para explicar que as referências alternativas ao Chile e à América Latina... são igualmente intencionadas. A parte vertebral de nosso assunto concerne, logicamente, 
ao Chile. Mas o problema econômico, social e político que nos preocupa é fundamentalmente latino-americano. Pode ser que, numa época, haja sido possível meditar sobre estes problemas, restringindo-se à faixa territorial entre os Andes, o deserto e o mar. Hoje, isso não é possível. O futuro da América é um só e cada país deve resolver seus problemas tendo sempre na mente a unidade dos povos da América (DE, vol. III, n. 1-2, 1963, p. 5).

A identidade da América Latina foi focalizada, com freqüência, através da história da região. Tema de muitos artigos publicados, ela constituiu o dossiê de alguns números da revista, como no caso do volume 3, de abril-setembro de 1963. Os editores responsáveis por esse fascículo, Roberto Cortes Condes e Ezequiel Gallo, apontaram as dificuldades para o crescimento evidenciadas pelos países latino-americanos como as razões que tornavam necessária a análise da formação histórica dos mesmos.

Três temas apareceram como norteadores das análises sobre a história da América Latina: a modernização da estrutura econômico-social promovida pela inserção da região na divisão internacional do trabalho, o desenvolvimento industrial que se iniciou no mesmo período e a manutenção da estrutura da propriedade da terra herdada dos períodos colonial e proto-independente.

A modernização da estrutura produtiva, realizada a partir da segunda metade do século XIX e primeiras décadas do século XX, foi vista como promotora de mudanças na economia e sociedade, mas preservou elementos da estrutura colonial, como o latifúndio e a economia agro-exportadora, considerados os principais responsáveis pelo atraso do desenvolvimento latino-americano. Nesse sentido, o texto de Scobie (1963) "Uma revolución agrícola em la Argentina" é exemplar, bem como o de Giberti (1962) "El desarrollo agropecuário".

Cepalinos e adeptos da teoria da modernização destacaram a industrialização como promotora do desenvolvimento. Para os primeiros, principalmente, o foco primordial a ser analisado acerca do processo de industrialização deveria ser o surgimento da indústria nacional voltada para o consumo interno e formada por capitais nacionais, como destaca Cortes Conde (1963) no artigo "Problemas del crecimiento industrial de la Argentina (1870-1914)".

A estrutura agrária arcaica, baseada na concentração da terra nas mãos de poucos proprietários e na baixa produtividade, bem como a desestruturação sócio-econômica e cultural por que passaram as populações nativas desde o período colonial, foram apontadas, como nos demais periódicos, como fatores responsáveis pelos baixos índices de desenvolvimento alcançado pelos países da 
região. Para demonstrar a identificação com essa linha de interpretação, a revista publicou artigos do historiador francês François Chevalier, intitulados "La gran propriedad em México desde siglo XVI hasta comienzos del siglo XIX" (1963) e "Los problemas agrários em la América Latina de tradición indígena" (1966).

\section{Conclusão}

Os intelectuais latino-americanos, nos anos 60 do século passado, preocuparam-se em refletir sobre a identidade latino-americana, tema que se fazia presente no imaginário coletivo da época. Concebendo-a como uma unidade - a nação latino-americana dotada de elementos econômicos, sociais, políticos e culturais comuns, trataram de representá-la em suas análises que focalizaram tanto o passado quanto o momento presente da região.

Mesmo com estilos diferentes, os mexicanos mais ensaístas e o argentino mais investigativo, os três periódicos abordaram temas semelhantes, como a dependência ou o imperialismo, as estruturas agrárias arcaicas e a fraca industrialização, como elementos que embasam essa identidade comum. Os intelectuais que neles publicaram mostraram-se envolvidos com a problemática latinoamericana, com a necessidade de alcançar uma maior compreensão da América Latina subdesenvolvida em que viviam, e com a busca de um caminho para o desenvolvimento da região.

Portanto, ao integrar todos os países a características e problemas comuns e apontar para a necessidade da colaboração entre os mesmos, as redes de intelectuais que se formaram deram a entender que havia uma identidade latino-americana, embasada em sentimentos de pertencimento e de alteridade que se espraiavam em toda a região.

\section{Referências bibliográficas}

ALBA, Victor. "La Nueva Clase Media Latinoamericana”. Revista Mexicana de Sociología, México: UNAM, vol. XXII, n. 3, 1960.

ALLENDE, Salvador. "Significado de la Conquista de un Gobierno Popular para Chile”. Cuadernos Americanos, México: UNAM, vol. CXXXVI, n. 5, 1964.

ANDREWS, Oscar Alvares. "Caracteres Generales de las Sociedades Latinoamericanas". Revista Mexicana de Sociología. México: UNAM, vol. XIX, n. 2, 1957. 
ARCINIEGAS, Germán. "Una presentación de América Latina". Cuadernos Americanos, México: UNAM, vol. CXLII, n. 5, 1965.

ARGUEDAS, Sol. "El saldo de las Elecciones Chilenas". Cuadernos Americanos, México: UNAM, vol. CXXXVIII, nº 1, ano XIX, 1965.

UNAM, vol. CXLVI, n. 3, 1966.

"Dónde está Che Guevara?". Cudernos Americanos, México:

BACKZO, Bronislaw. Imaginação social. In: Enciclopédia Einaudi. vol. 5. Lisboa: Imprensa Nacional-Casa da Moeda, 1985.

BELFRAGE, Cedric. "El Ecuador em 1963". Cuadernos Americanos, México: UNAM, vol. CXXXII, n. 1, 1964.

BOURDIEU, Pierre. O poder simbólico. Lisboa: Difel, 1989.

CANCINO, Hugo. "Los intelectuales latinoamericanos entre la modernidad y la tradición - siglos XIX y XX". Cuadernos de Historia Latinoamericana, Espanha: Imprensa Fareso S. A., 2004.

CENDRERO, Rosa. "Cusminski. Sobre los intentos de Integración Latinoamericana". Cuadernos Americanos, México: UNAM, vol. CXLI, n. 4, 1965.

CHAVALIER, François. "La gran propiedad en Mexico desde siglo XVI hasta comienzos del siglo XIX”. Desarrollo Econômico, Buenos Aires: I.D.E.S, vol. 3, n. 1-2, abril/setembro de 1963.

"Los Problemas Agrarios en la América Latina de Tradición Indígena”. Desarrollo Economico, Buenos Aires: I.D.E.S, vol. 6, n. 22-23, julho/dezembro de 1963.

CONDE, Roberto Cortes. "Problemas del Crescimento industrial de la Argetina”. Desarrollo Econômico, Bueno s Aires: I.D.E.S, vol. 3, n. 1-2, abril/setembro de 1963.

DENIS, Manuel Maldonado. "Puerto Rico y la América Latina". Cuadernos Americanos, México: UNAM, vol. CXXIX, n. 4, 1963.

DIEZ, Alvaro Mendoza. "Los Doctores y la Revolución en la América Latina". Revista Mexicana de Sociología, México: UNAM, vol. XXII, n. 3, 1960.

ESTENÓS, Roberto Mac Lean. "Economía y Trabajo de los Aborígenes del Perú”. Revista Mexicana de Sociología, México: UNAM, vol. XX, n. 2, 1958.

GAITÁN, Ricardo Torres. "Perspectivas de la Conferencia Mundial sobre desarrollo y comercio". Cuadernos Americanos, México: UNAM, vol. CXXXV, n. 4,1964 .

GARCIA, Antonio. "Hacia una teoria de los países atrasados". Cuadernos Americanos, México: UNAM, vol. LXXX, n. 2, 1955.

GILBERTI, Horacio. "El desarrollo agropecuário". Desarrollo Econômico, Buenos Aires: I.D.E.S, vol. 2, n. 1, abril/junho de 1962.

GÓMES, Ramón Ramires. "El informe Prebisch y la realidad latinoamericana". Cuadernos Americanos, México: UNAM, vol. CXXXI, n. 6, 1963. 
HERZOG, Jesús Silva. "México a 50 años de su Revolución". Cuadernos Americanos, México: UNAM, vol. CXXXII, n. 1, 1964.

HORÁCIO, Gilberti. "El desarrollo agropecuário. Desarrollo Econômico, Buenos Aires: I.D.E.S, vol. 2, n. 1, abril/junho de 1962.

"Algo más sobre el Ecuador". Cuadernos Americanos, México: UNAM, vol. CXXXII, n. 1, 1964

JAMES, R. Scobie. "Una revolución agrícola en la Argentina". Desarrollo Econômico, Buenos Aires: I.D.E.S, vol. 3, n. 1-2, abril/setembro de 1963.

LARREA, Julio. "La educación y la vida internacional en la América Latina". Cuadernos Americanos, México: UNAM, vol. CXXX, n. 5, 1963.

ORTEGA, Julián Izquierdo. "Inquietud sin Tregua, de Jesús Silva Herzog Cuadernos Americanos, 1965”. Cuadernos Americanos, México: UNAM, vol. CXLVI, n. 3, 1966.

ORTIZ, Yolanda. “Algunas Dificultades de Adaptación de las Poblaciones Rurales al Pasar al Medio Urbano en los Países Latinoamericanos y Especialmente en Colombia”. Revista Mexicana de Sociología, México: UNAM, vol. XIX, n. 1, 1957.

PALÁCIOS, Alfredo L. "Una Revolución Auténtica en Nuestra América". Cuadernos Americanos, México: UNAM, vol. CXII, n. 5, 1960.

PORTILLA, Miguel Leon. "Algunos Tipos de Planificación Indigenista". Revista Mexicana de Sociología, México: UNAM, vol. XXII, n. 2, 1960.

RAMA, Carlos M. José Pedro Varela. "Primer Sociólogo Uruguayo". Revista Mexicana de Sociologia, México: UNAM, vol. XIX, n. 2, 1957.

"América Latina y la Primeira Internacional". Cuadernos Americanos, México: UNAM, vol. CXXXVIII, n. 1, 1965.

SALOMÓN, Noel. "La crítica del sistema colonial de la Nueva Espana en El Periquillo Sarmiento". Cuadernos Americanos, México: UNAM, vol. CXXXVIII, n. 1, 1965.

SAINT-LOUIS, René. "La Constituición de 1801 em Haiti, em sus Relaciones com la Realidade Social”. Revista Mexicana de Sociología, México: UNAM, vol. XXI, n. 1, 1959.

SIRINELLI, Jean-Françóis. Os intelectuais. In: RÉMOND, René (org). Por uma história política. Rio de Janeiro: Editora UFRJ, 1996.

SOLARI, Aldo E. 'El fenómeno del 'Envejecimiento' en la población Uruguaya”. Revista Mexicana de Sociología, México: UNAM, vol. XIX, n. 2, 1957.

WHITE, William Foote. "Algunos Problemas Humanos del Desarrollo Industrial". Revista Mexicana de Sociología, México: UNAM, vol. XXIII, n. 3, 1961.

VALDEZ, Abraham Gustavo. “Adolfo Otero y su Contribución a la Sociología Boliviana”. Revista Mexicana de Sociología, México: UNAM, vol. XXI, n. 1, 1959. 
VELIZ, Claudio. "La Mesa de Tres Patas." Desarrollo Económico. Buenos Aires: I.D.E.S, vol. III, n. 1-2, 1963.

VILLEGAS, Oscar Uribi. "Una Relación Primaria Entre lo Académico y lo Social Como Problema de las Sociedades y de la Sociología en Latinoamérica". Revista Mexicana de Sociología, México: UNAM, vol. XX, n. 2, 1958.

"Primeras Reflexiones sobre la Indispensable Conceptuación Sociológica de los Movimientos Independentistas". Revista Mexicana de Sociología, México: UNAM, vol. XXII, n. 2, 1960.

ZEA Leopoldo. "La América Latina en el siglo XX". Cuadernos Americanos, México: UNAM, vol. CXXXII, n. 1, 1964.

"Latino América en la formación de nuestro tiempo". Cuadernos Americanos, México vol. CXLII, n. 5, 1965.

Recebido em 5 de julho de 2007. 